\title{
MicroRNAs, epigenetics and disease
}

Silahtaroglu, Asli; Stenvang, Jan

Published in:

Essays in Biochemistry

DOI:

10.1042/bse0480165

Publication date:

2010

Document version

Early version, also known as pre-print

Citation for published version (APA):

Silahtaroglu, A., \& Stenvang, J. (2010). MicroRNAs, epigenetics and disease. Essays in Biochemistry, 48(1), 165-185. https://doi.org/10.1042/bse0480165 


\title{
MicroRNAs, epigenetics and disease
}

\author{
Asli Silahtaroglu*1 and Jan Stenvang $\dagger$ \\ *Wilhelm Johannsen Centre for Functional Genome Research, \\ Department of Cellular and Molecular Medicine, University of \\ Copenhagen, Blegdamsvej 3, DK-2200, Copenhagen N, Denmark, \\ and $\dagger$ Department of Veterinary Disease Biology, Faculty of Life \\ Sciences (LIFE), University of Copenhagen, Dyrlagevej 88, 1870 \\ Frederiksberg C, Denmark
}

\begin{abstract}
Epigenetics is defined as the heritable chances that affect gene expression without changing the DNA sequence. Epigenetic regulation of gene expression can be through different mechanisms such as DNA methylation, histone modifications and nucleosome positioning. MicroRNAs are short RNA molecules which do not code for a protein but have a role in posttranscriptional silencing of multiple target genes by binding to their $3^{\prime}$ UTRs (untranslated regions). Both epigenetic mechanisms, such as DNA methylation and histone modifications, and the microRNAs are crucial for normal differentiation, development and maintenance of tissue-specific gene expression. These mechanisms also explain how cells with the same DNA content can differentiate into cells with different functions. Changes in epigenetic processes can lead to changes in gene function, cancer formation and progression, as well as other diseases. In the present chapter we will mainly focus on microRNAs and methylation and their implications in human disease, mainly in cancer.
\end{abstract}

${ }^{1}$ To whom correspondence should be addressed (email asli@sund.ku.dk). 


\section{Introduction to microRNAs}

miRNAs (microRNAs) are a class of short (approx. $22 \mathrm{nt}$ ) endogenous noncoding RNAs that act as post-transcriptional regulators of gene expression. According to the September 2009 release of the microRNA database mirbase (http://www.mirbase.org/) there are 10883 miRNA entries from vertebrates, insects, plants and viruses discovered either by cloning or bioinformatics [1]. Among them 721 are detected in humans. The first member of the miRNA family, lin-4, was originally identified in Caenorbabditis elegans as a developmental timing regulator [2]. miRNAs play fundamental roles in the control of many biological processes such as growth, development, differentiation, proliferation and cell death $[2,3]$. They perform these functions by repression of their target genes. Each miRNA may target several hundred mRNAs and more than $60 \%$ of the mRNAs are predicted to have a miRNAbinding site in their 3' UTR (3' untranslated region). The huge number of miRNAs identified and evidence accumulated over the years indicate that a vast number of normal and pathological mechanisms are controlled by miRNA-mediated regulatory networks (reviewed in $[4,5]$ ).

\section{Genomic organization, biogenesis and function}

miRNAs can be intergenic, intronic or exonic. Intergenic miRNAs have either their own promoters (monocistronic) or share the same promoter (polycistronic), whereas the intronic miRNAs are present either singly or in clusters using the promoter of their host gene. miRNAs are transcribed in the nucleus by RNA polymerase II. They are 5' capped and 3' polyadenylated. The maturation of miRNAs requires two endonucleolytic cleavage steps by RNase III-like enzymes: Drosha and Dicer. Following transcription, Drosha processes the primary miRNA transcript (pri-miRNA), which can be several kilobases long, into a 60-100 nt hairpin structure named the precursor-miRNA (pre-miRNA). Pre-miRNAs are folded into mini-helical structures to be recognized by exportin-5, the nuclear export factor carrying the pre-miRNAs from the nucleus to the cytoplasm. In the cytoplasm, the pre-miRNA hairpin is cleaved at the loop end by Dicer, thereby creating a 22 nt RNA duplex comprising the mature miRNA guide strand and the miRNA* passenger strand. The mature miRNA is loaded into the RISC (RNA-induced silencing complex), whereas the passenger strand is degraded (Figure 1). The exact details of the miRNA biogenesis mechanism are still to be investigated, and much less is known about the mechanisms regulating the expression of miRNAs. Recent studies point out that not all miRNAs are created by the same mechanisms. After being loaded into the RISC complex mature miRNAs are directed to their binding sites in their target mRNAs. In broad terms, this binding leads to repression of mRNA translation by one of the following mechanisms: translational block by folding the mRNA in an inactive steric conformation, deadenylation and destabilization of the 


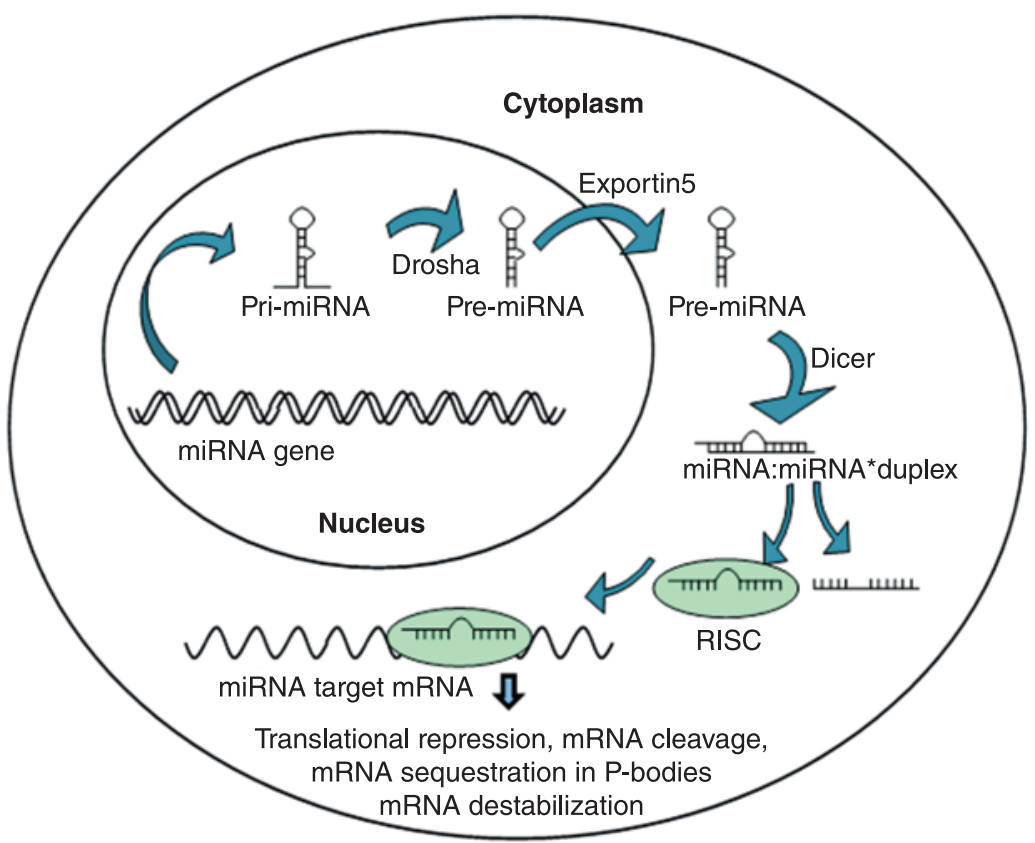

Figure I. Schematic representation of the process from transcription of a miRNA gene in the nucleus to mature regulatory miRNA binding to target mRNA in the cytosol

Upon binding to the target mRNA the process may be negatively regulated by different mechanisms, i.e. translational repression, mRNA destabilization, mRNA cleavage or sequestration in P-bodies.

mRNA, cleavage of the mRNA or sequestration in P-bodies (processing bodies) (reviewed in $[4,6,7]$ ).

\section{miRNAs regulate important biological processes}

For many biological functions it is very important to have the miRNA expression in balance. Developmental timing, differentiation, organogenesis, cell proliferation, apoptosis, differentiation of embryonic stem cells, limb development, synaptic development and plasticity, skin differentiation, cardiogenesis, normal immune function and regulation of insulin secretion in the pancreas are some of the biological functions where miRNAs play a crucial role (reviewed in [7]).

\section{miRNA and disease}

In the last decade it has become clear that aberrant miRNA deregulation and expression is observed in most human malignancies, although it is often not clear whether this deregulation is the cause or the effect of the disease. Some of the most investigated malignancies are cancers, dysfunctional heart conditions, metabolic diseases and viral infections. Very recently a knowledge-base on 


\section{Table I. Overview of various miRNAs that are either down-regulated or up-regulated in human tumour tissue}

AML, acute myeloid leukaemia; CLL, chronic lymphocytic leukaemia.

\begin{tabular}{|c|c|c|}
\hline miRNA & Tumour tissue & $\begin{array}{l}\text { Changed expression in } \\
\text { tumours }\end{array}$ \\
\hline Let-7 family & $\begin{array}{l}\text { Lung, breast, prostate, colon, gastric, } \\
\text { ovary, CLL }\end{array}$ & Down-regulated \\
\hline miR-I0I & Prostate, liver and bladder & Down-regulated \\
\hline miR-I22a & Liver & Down-regulated \\
\hline miR-I43 & Colon, breast, lung, cervix, B-cell & Down-regulated \\
\hline \multicolumn{3}{|l|}{ miR-I45 } \\
\hline miR-I5a & $\begin{array}{l}\text { CLL, prostate, pancreas and multiple } \\
\text { myeloma }\end{array}$ & Down-regulated \\
\hline \multicolumn{3}{|l|}{ miR-I6-I } \\
\hline miR-I55 & $\begin{array}{l}\text { CLL, Burkitt's lymphoma, lung, breast, } \\
\text { pancreas and colon }\end{array}$ & Up-regulated \\
\hline miR-22I & Leukaemia & Down-regulated \\
\hline \multicolumn{3}{|l|}{ miR-222 } \\
\hline miR-29 family & CLL, AML, breast, colon and lung & Down-regulated \\
\hline miR-34 family & Pancreas, colon, breast and liver & Down-regulated \\
\hline miR-372 & Testis & Up-regulated \\
\hline \multicolumn{3}{|l|}{ miR-373 } \\
\hline miR-17-92 cluster & $\begin{array}{l}\text { Lymphomas, breast, lung, colon, } \\
\text { stomach and pancreas }\end{array}$ & Up-regulated \\
\hline $\begin{array}{l}\text { miR-106b-93-25 } \\
\text { cluster }\end{array}$ & $\begin{array}{l}\text { Gastric, colon, prostate and } \\
\text { neuroblastoma }\end{array}$ & Up-regulated \\
\hline miR-2I & $\begin{array}{l}\text { Glioblastoma, ALM, CLL, Burkitt's } \\
\text { lymphoma, breast, colon, pancreas, lung, } \\
\text { prostate, liver and stomach, cervix, } \\
\text { head and neck cancers }\end{array}$ & Up-regulated \\
\hline miR-22I & CLL, thyroid, liver and glioblastoma & Up-regulated \\
\hline miR-222 & & \\
\hline
\end{tabular}

the aberrant expression of miRNAs in various diseases was introduced [8]. In cancers, miRNAs can act either as oncogenes or tumour suppressors, and a multitude of papers have investigated the differential expression of miRNAs in tumour tissues and their function in cancer cells and metastatic potential (see Table 1 for an overview). Many miRNAs act as tumour suppressor genes and they are frequently silenced in cancers. However, the underlying mechanism for this is less clear. One explanation is epigenetic silencing of miRNA genes and this has now been described in various cancers for several miRNAs. 
Mechanisms such as change in turnover rate or DNA copy number could be other reasons for differential expression of miRNAs which need to be further investigated $[9,10]$.

\section{Introduction to miRNA and epigenetics}

Epigenetic phenomenons such as DNA methylation of CpG islands in promoter regions of genes and histone modifications are well known to regulate gene expression. The major epigenetic changes in cancer are aberrant DNA hypermethylation of tumour suppressor genes, global genomic DNA hypomethylation and disruption of the histone modification patterns.

Like classical protein coding genes, miRNA genes are also subject to epigenetic regulation and miRNAs can also regulate various components of the epigenetic machinery. For a detailed review, see [11].

\section{Epigenetic regulation of miRNA expression in cancer}

Several miRNAs are down-regulated in cancer and act as bona fide tumour suppressor genes, and therefore these miRNAs are obvious candidates for epigenetic silencing. High-quality papers have been published on the impact of epigenetic regulation of miRNA genes with regard to cell proliferation, apoptosis, tumour suppressor or oncogenic effects both in cell culture systems, in vivo models and in various human primary tumours. The epigenetic status has also been correlated with metastatic status and with survival of cancer patients, which will be the focus of this part of the chapter. An up-to-date overview is presented in Table 2.

The concept of controlling miRNA expression by epigenetic mechanisms may be as widespread as for protein coding genes, since half of the miRNA genes are associated with $\mathrm{CpG}$ islands and miRNA gene methylation is detected with high frequency in normal and malignant cells [12].

A common approach to identifying epigenetically regulated miRNAs has been to treat cancer cells with inhibitors of DNA methylation (e.g. 5-azacytidine) and/or histone deacetylases [e.g. PBA (4-phenylbutyric acid) or TSA (trichostatin A)] and compare miRNA expression to that in untreated cells.

This approach was applied in the first two high-impact publications in this field from 2006, which identified a number of epigenetically regulated miRNAs in breast and bladder cancer cells $[13,14]$.

It has turned out that epigenetic regulation of miRNA expression is a common hallmark in human cancers and that epigenetic tags are associated with metastatic status and clinically relevant endpoints, such as disease-free survival and overall survival, thereby suggesting their use as biomarkers in cancer detection, prognosis, monitoring and predicting response to treatment.

In CRC (colorectal cancer), epigenetically regulated miRNAs have been indentified in both cell lines and in tumour tissues. The expression of miR-342 was found to be regulated by $\mathrm{CpG}$ island methylation. Interestingly, 


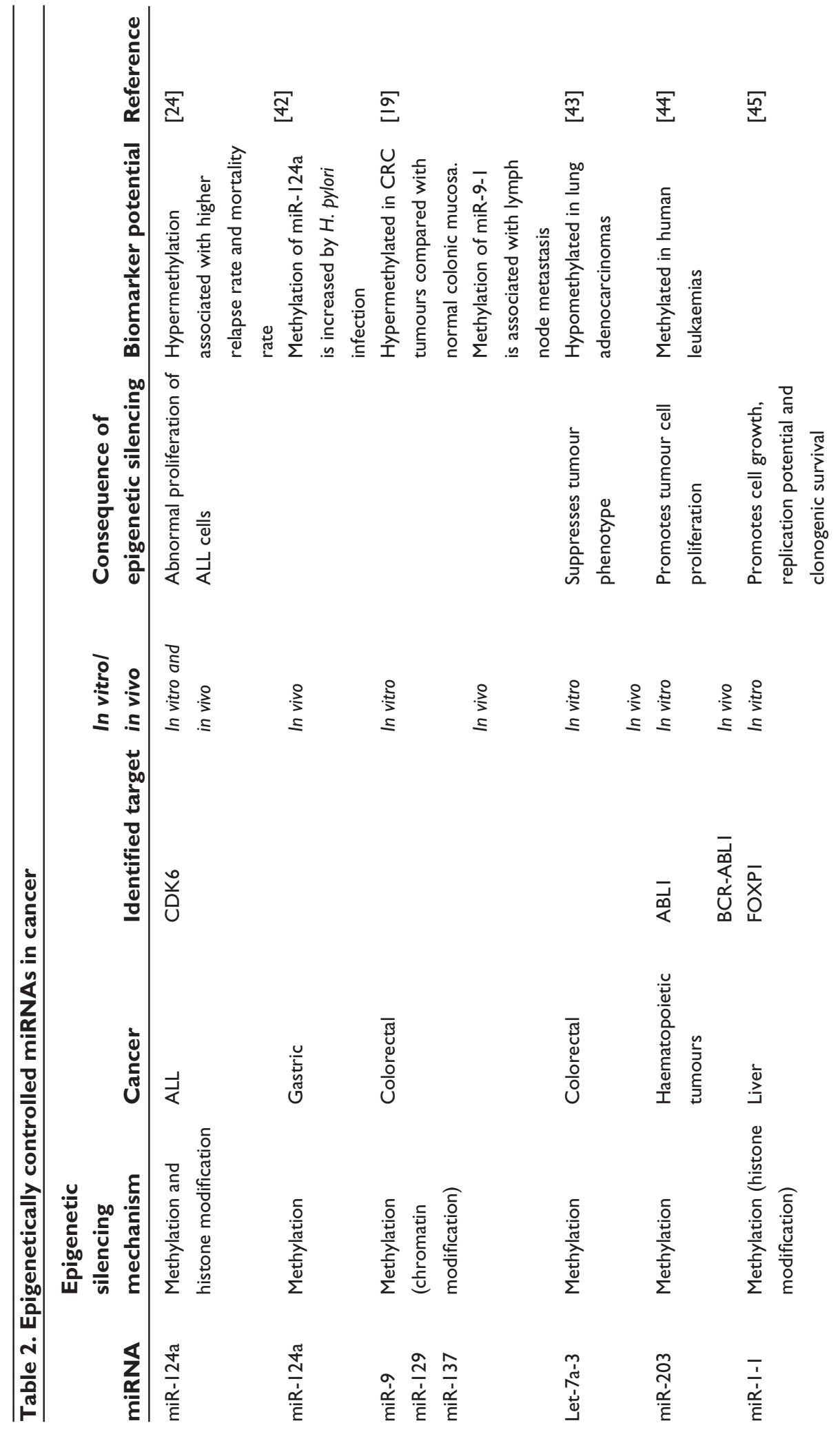

(C) The Authors Journal compilation (c) 2010 Biochemical Society 

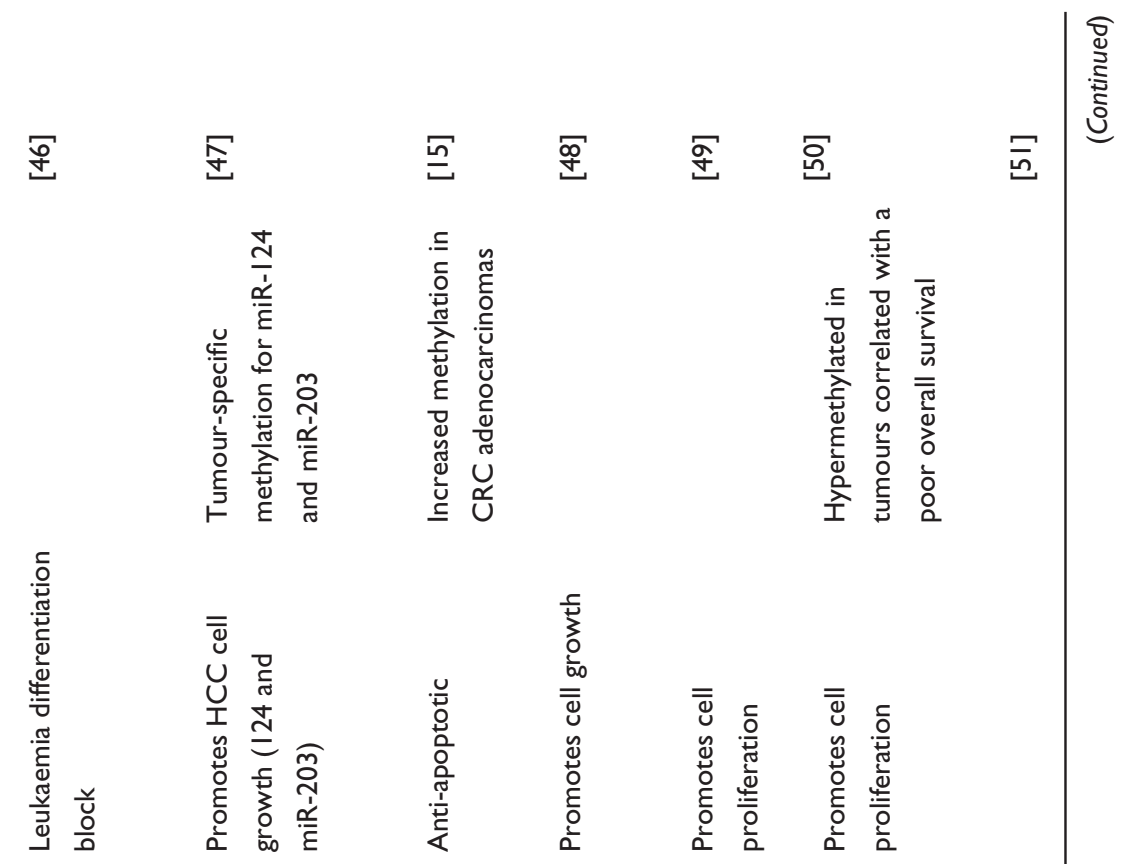

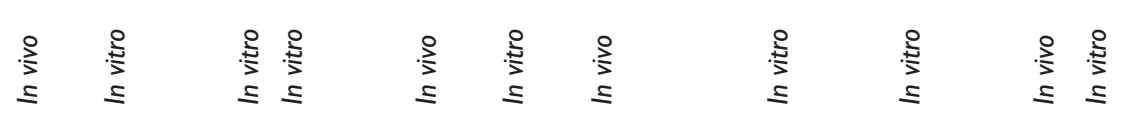

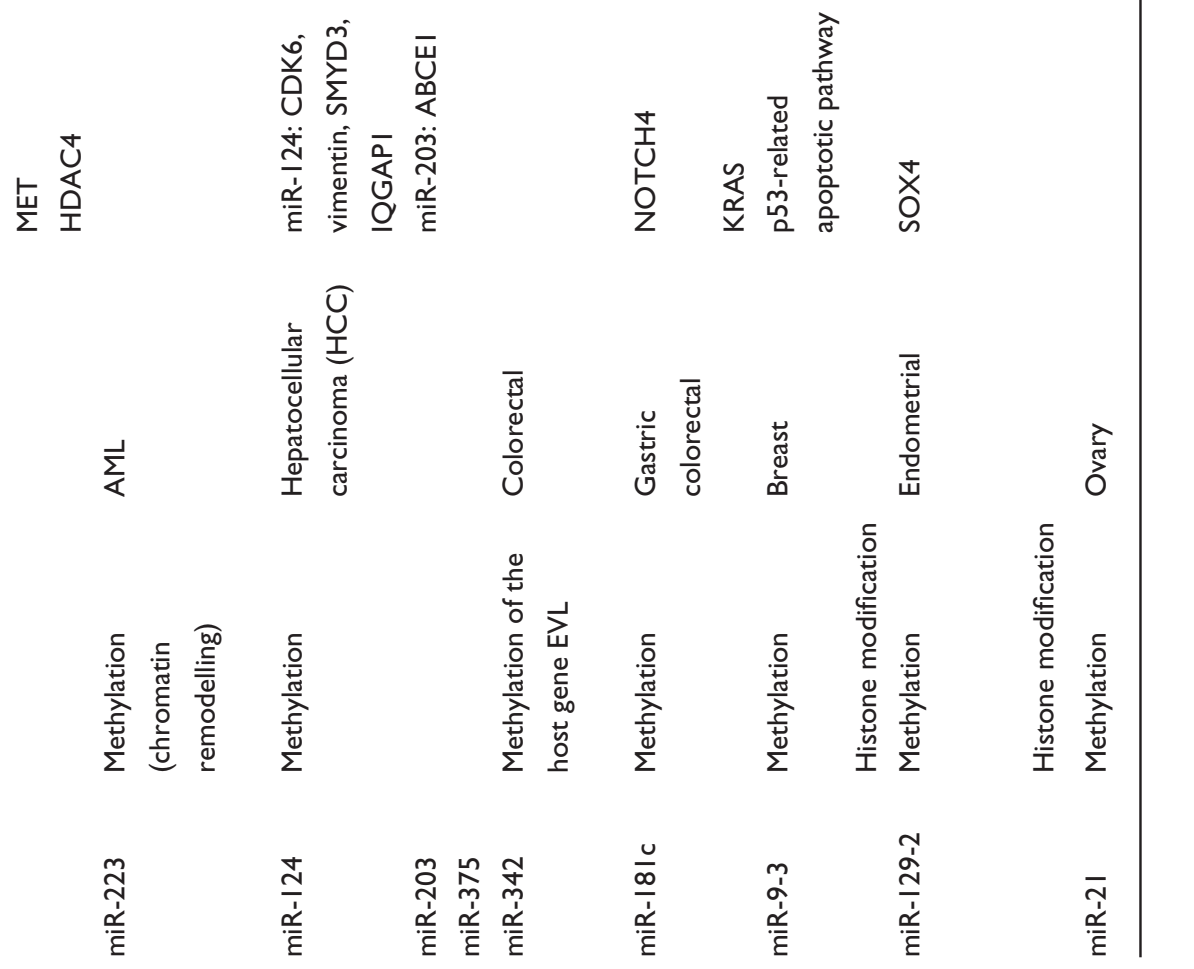


స్․․

气

它

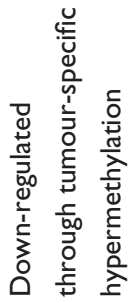

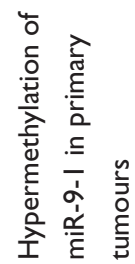

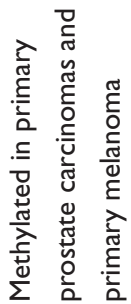

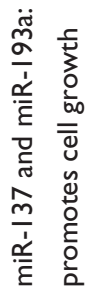

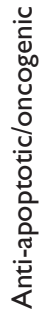

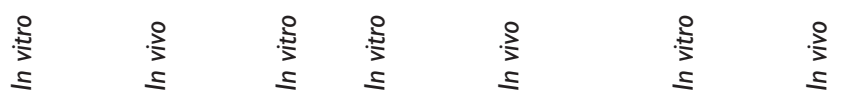

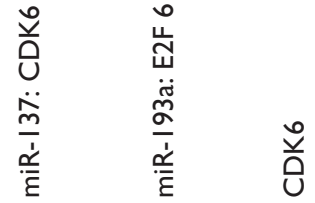

$\frac{\vartheta}{\cup}$

ฮั

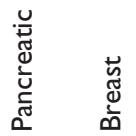

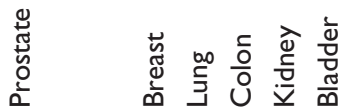

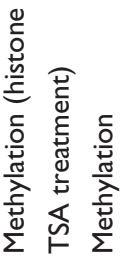

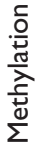

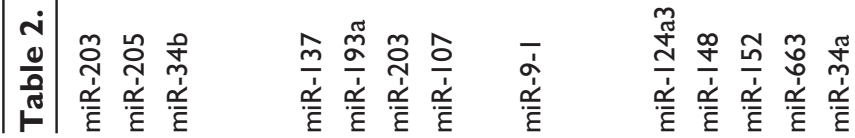




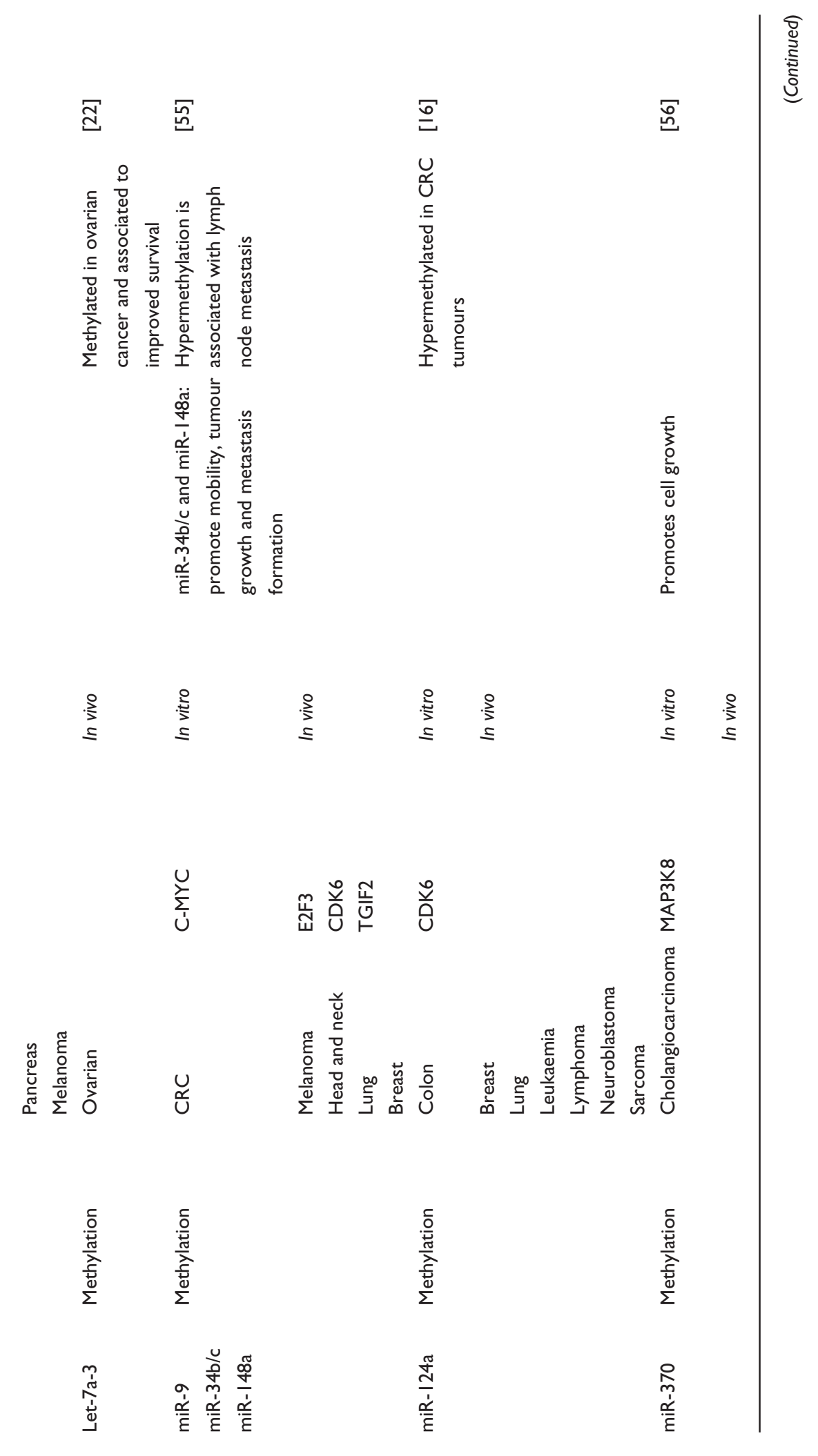

(C) The Authors Journal compilation (c) 2010 Biochemical Society 


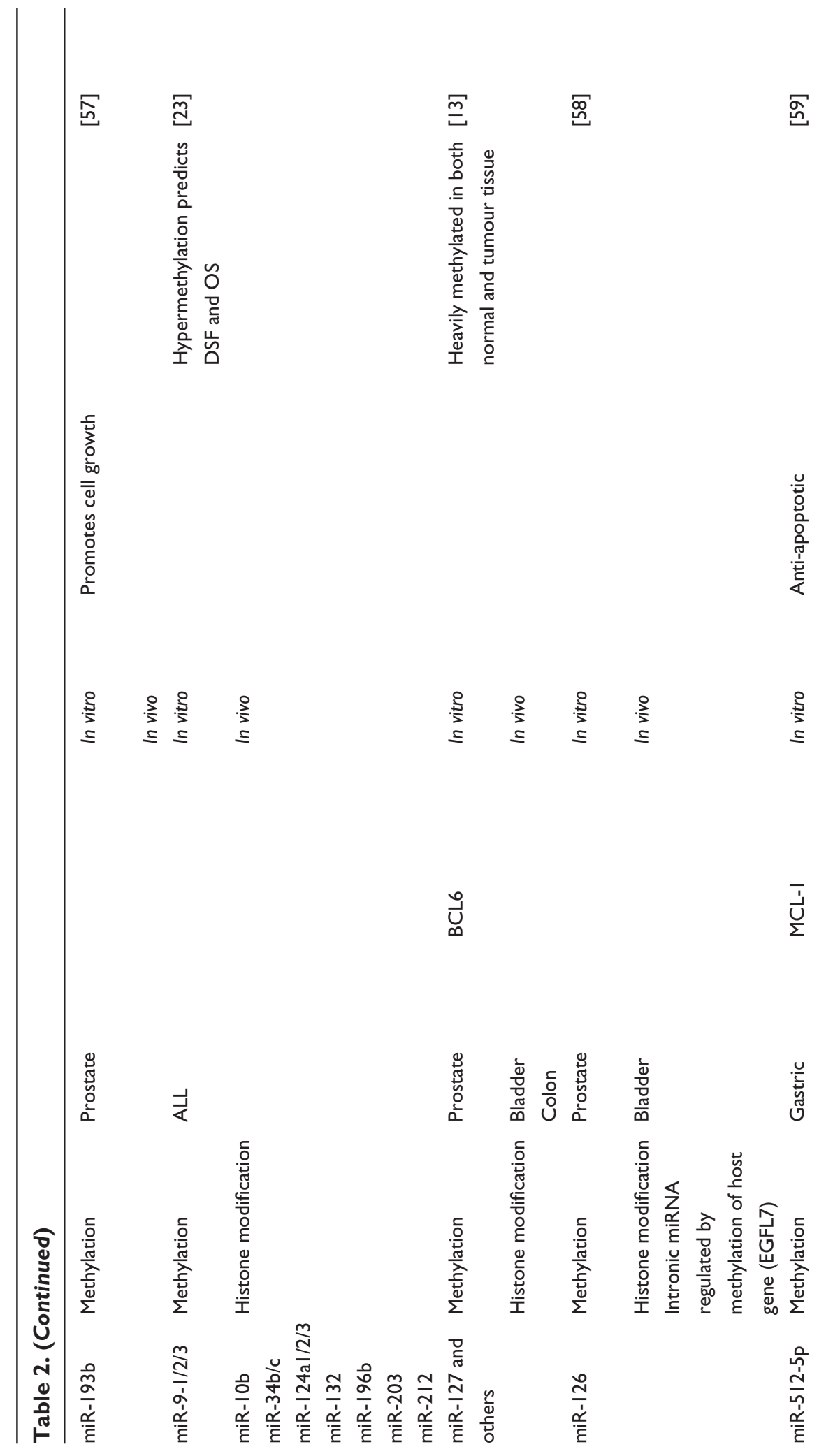

(c) The Authors Journal compilation (c) 2010 Biochemical Society 


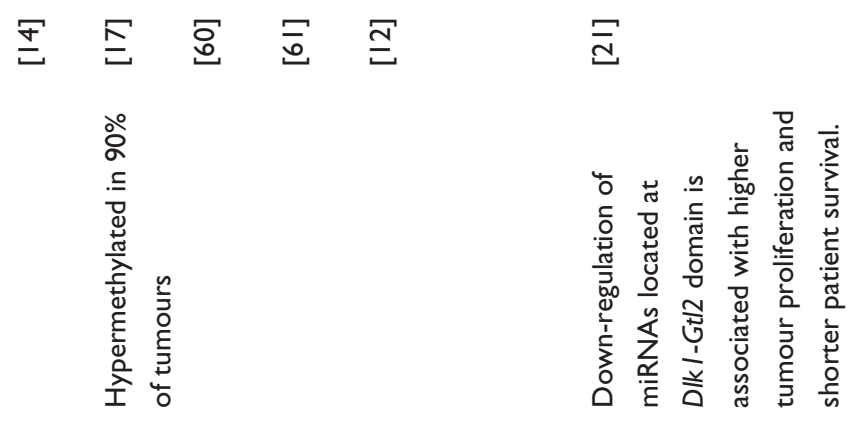

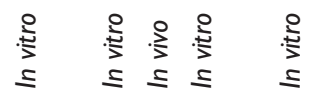

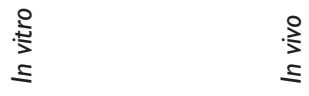

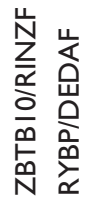
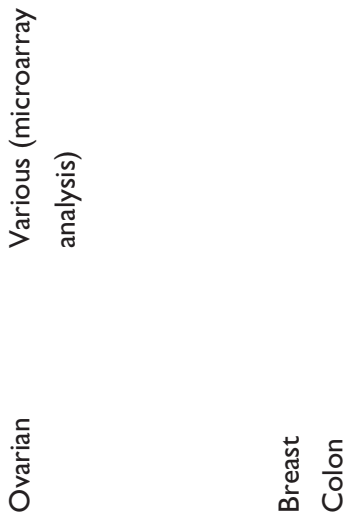

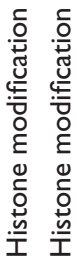

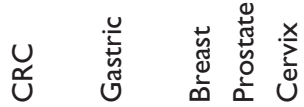

$\frac{0}{0} \overbrace{}^{\frac{0}{2}}$

嵌

Фัฐ

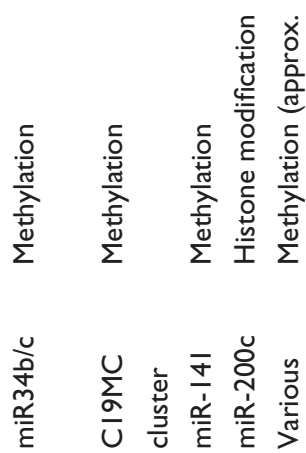

$\begin{array}{lll}\dot{x} & \mathscr{y} & 0 \\ 0 & 0 & 0 \\ 0 & 0 & 0 \\ 0 & 0 & 0\end{array}$

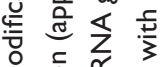

号 导

은 矛

$\frac{\text { co }}{\frac{\pi}{2}}$

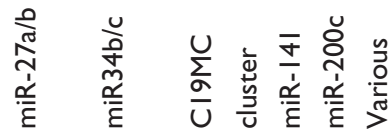

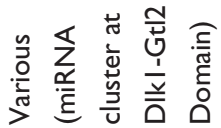


methylation of miR-342 may be specific to CRC, since in vitro studies employing 40 non-CRC cell lines only found partial methylation in a single cell line. Analysis of tissue indicated that methylation of miR-342 may be an early event in CRC since methylation was detected in $86 \%$ of CRC adenocarcinomas and in $67 \%$ of adenomas [15]. Comparison of normal and colon cancer tissues has shown that miR-124a is hypermethylated in $75 \%$ of the tumours $(n=56)$ [14]. Methylation of miR-124a was also found in tumours from the lungs $(48 \%$, $n=27)$ and breast (32\%, $n=22)$, but not in neuroblastomas or sarcomas [16]. Analysis of primary CRC tumours $(n=111)$ and adjacent normal colon $(n=17)$ found that miR-34b/c was methylated in $90 \%$ of the primary CRC tissues and very limited methylation was found in the normal mucosa [17].

In primary breast cancer specimens, aberrant hypermethylation has been shown for miR-9-1, miR-124a3, miR-148, miR-152 and miR-663 in 34-86\% of cases in a series of 71 primary human breast cancer specimens [18]. The miR-9-1 gene is hypermethylated in pre-invasive intraductal lesions, suggesting that hypermethylation of miR-9-1 is an early and frequent event in breast cancer development.

Two reports have associated methylation of miRNA genes with metastatic status of cancer patients.

Bandres et al. [19] identified five down-regulated miRNAs in primary CRC, which were located in the vicinity $(<1000 \mathrm{bp})$ of a $\mathrm{CpG}$ island. Methylation status for three of these were analysed in primary CRC samples and adjacent normal tissue, and miR-9-1, miR-129-2 and miR-137 were methylated in $56 \%(n=36), 91 \%(n=34)$ and $100 \%(n=31)$ of primary CRC cases respectively. Methylation of miR-9-1 was totally absent in histological normal mucosa and methylation was more frequent in stage III and IV compared with stage I and II. Importantly, methylation status of miR-9-1 was associated with regional nodal invasion, vascular invasion and metastasis in a group of 32 patients ( 16 non-methylated and 20 methylated).

In a recent report, direct relation of miRNA hypermethylation and metastasis was explored [20]. Cell lines established from lymph node metastasis were treated with 5-azacytidine and the miRNA expression relative to untreated cells was investigated. These experiments identified 16 hypermethylated and up-regulated miRNAs, located in the proximity of a $\mathrm{CpG}$ island. Comparison with methylation status of non-cancerous tissues further reduced the number of miRNAs displaying cancer-specific $\mathrm{CpG}$ island hypermethylation. The selected miRs - miR-148a, miR-34b/ c, and miR-9-1/2/3 - were tested in vitro and in vivo for their potential involvement in metastasis. Re-introduction of $\mathrm{miR}-34 \mathrm{~b} / \mathrm{c}$ and $\mathrm{miR}-148$ into a metastatic carcinoma cell line, which is hypermethylated and silenced for $\mathrm{miR}-34 \mathrm{~b} / \mathrm{c}$ and $\mathrm{miR}-148$ expression, reduced the migratory capability of the cancer cells. Likewise, experiments with nude mice showed that re-introduction of miR-34b/c and miR-148 caused reduced tumour growth and diminished metastatic potential of the metastatic carcinoma 
cell line. A collection of primary tumour samples $(n=278)$ from various tumour types were analysed and hypermethylation was undetectable in the corresponding normal tissue. Notably, hypermethylation of $\mathrm{miR}-34 \mathrm{~b} / \mathrm{c}$, miR-148 and miR-9-3 in primary tumours was significantly associated with those tumours that were positive for metastatic cancer cells in the corresponding lymph nodes $(n=207)$.

In a report focusing on ovarian cancer, eight miRNAs (miR-337, miR-368, miR-376a/b, miR-377, miR-410, miR-432, miR-495) located in the chromosome 14 miRNA cluster (Dlk1-Gtl2 domain) were identified as potential tumour suppressor genes regulated by DNA methylation [21]. An expression signature separated late-stage ovarian cancers $(n=73)$ into two distinct clusters. Patients belonging to the cluster with low expression of the eight miRNAs displayed higher tumour proliferation and had shorter 5-year survival. Analysis of other cancer types indicated that down-regulation of the chromosome 14 miRNA cluster may be an event common to many human epithelial tumours.

The let-7a-3 gene is located in a CpG island and its methylation status was analysed in 214 malignant tumours: no correlation between disease stage and tumour grade was detected [22]. Although the disease-free survival was not associated with methylation of let-7a-3, the patients with low let-7a-3 methylation $(n=138)$ had significantly worse overall survival than those with high methylation $(n=67)$.

Two reports from the same laboratory have analysed epigenetic regulation of miRNA expression in ALL (acute lymphoblastic leukaemia) and associated it with clinical outcome.

In ALL-derived cell lines, analysis of histone modifications around CpG islands located in the 5' UTR of miRNA genes identified 13 miRNA candidate genes for epigenetic silencing: miR-9-1/2/3, miR-10b, miR-34b/c, miR-124a1/ a2/a3, miR-132, miR-196b, miR-203 and miR-212 [23]. Methylation of at least one in 13 miRNA was found in $65 \%(n=353)$ of the ALL human tumours and was a strong and independent negative prognostic marker for disease-free survival and overall survival.

In ALL patients, miR-124 is regulated by $\mathrm{CpG}$ island hypermethylation and histone modifications, and re-introduction of miR-124a severely reduced tumorigenicity of ALL cells in a xenograft mouse model [24]. The miR-124a methylation status was analysed in 353 ALL patients and hypermethylation was found in 59\%; this correlated with decreased expression of miR-124a. Furthermore, hypermethylation significantly correlated with higher relapse and mortality rates, and multivariate analysis showed that miR-124a is an independent prognostic factor for both disease-free survival and overall survival.

Taken together, these results show that DNA demethylation and HDAC (histone deacetylase) inhibition can activate expression of miRNAs and further large-scale clinical investigations are clearly warranted. 


\section{miRNAs as regulators of epigenetic processes}

As well as being regulated by epigenetic mechanisms, miRNAs also play a role in controlling the chromatin structure by post-transcriptional regulation of chromatin-modifying enzymes (reviewed in $[11,25]$ ). Among the predicted human miRNA target genes there are a number of genes involved in epigenetic regulation, such as the methyl $\mathrm{CpG}$-binding proteins, HMTs (histone methyltransferases), chromodomain-containing proteins and HDACs [26]. This subset of miRNAs, which directly or indirectly regulate the expression levels of effectors of the epigenetic processes, have been termed 'epi-miRNAs' [11]. Aberrant regulation of miRNA expression plays an important and direct role in the aberrant epigenetic silencing of tumour suppressor genes by DNA methylation in human cancers (see Table 3).

DNA methylation patterns are laid down during development by DNMT3a and DNMT3b (where DNMT is DNA methyltransferase), whereas maintenance during replication is facilitated by DNMT1. The first direct link between a miRNA and the DNMTs was established between the miR-29 family (miR-29a/b/c) and DNMT3a and DNMT3b, and other miRNAs such as miR-148 and miR-143 have also been indicated as regulators of the methylation enzymes. In non-small cell carcinoma of the lung, miR-29 is down-regulated, whereas the DNMT3A and DNMT3B expression is increased. Re-expression of miR-29 is shown to disrupt the de novo DNA methylation and caused general hypomethylation, leading to expression of tumour suppressor genes that are silenced by methylation, which resulted in apoptosis in cancer cells both in vitro and in vivo. This study indicated that miR-29 regulates the DNMT3 genes in lung cancer and revealed a new mechanism whereby the miRNAs indirectly regulate the gene expression through direct regulation of epigenetic mechanisms [27]. Another group has shown that overexpression of miR-29b in AML (acute myeloid leukaemia) cells resulted in marked reduction of DNMT1, DNMT3A and DNMT3B at both the RNA and protein levels. They concluded that the expression of $m i R-29 b$ promoted DNA hypomethylation not only through direct targeting of DNMT3a and DNMT3b, but also by decreasing the DNMT1 expression indirectly via down-regulation of $S p 1$, a known transactivating factor of the DNMT1 gene [28].

Furthermore, miR-143 regulates DNMT3a in CRC cells, whereas miR-148a and miR-148b represses Dnmt3b expression in mouse cells through binding to a highly conserved sequence in its coding region rather than the 3 ' UTR [29,30]. Benetti et al. [31] proposed a new regulatory pathway for DNA methylation involving the mammalian miR-290 cluster (miR-290, miR-291-3p, miR-291-5p, miR-292-3p, miR-292-5p, miR-293, miR-294 and miR-295) as an important regulator of $\mathrm{Rbl2}$, which in turn acts as a transcriptional repressor of Dnmt3a and Dnmt3b causing hypomethylation in the genome, especially in the telomeres. The whole cluster is shown to be down-regulated in Dicer-null cells in mouse, whereas $\mathrm{Rb} 12$ is increased in expression leading to repression of Dnmt3a and Dnmt3b causing DNA methylation defects [31]. However, the 


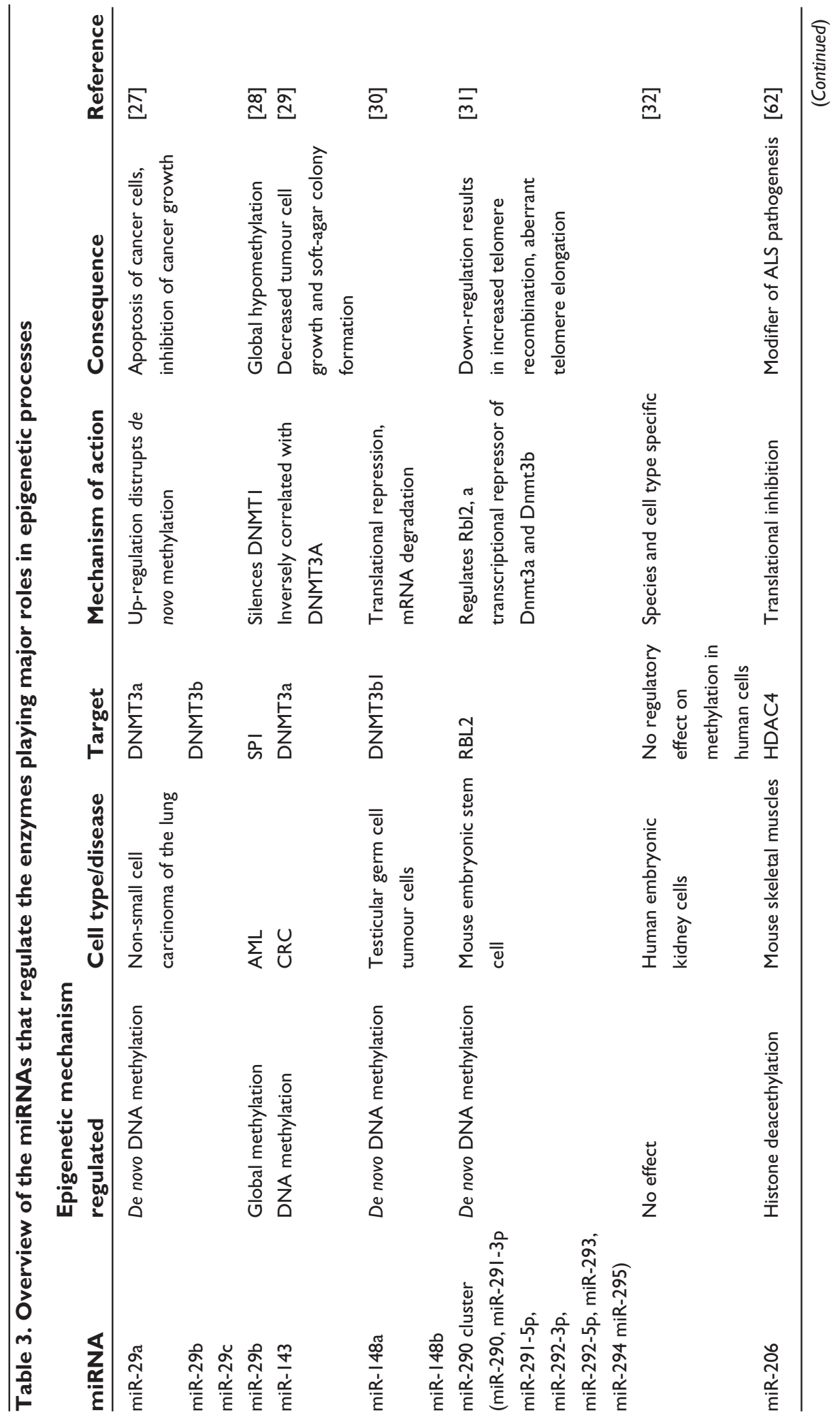

(C) The Authors Journal compilation (c) 2010 Biochemical Society 


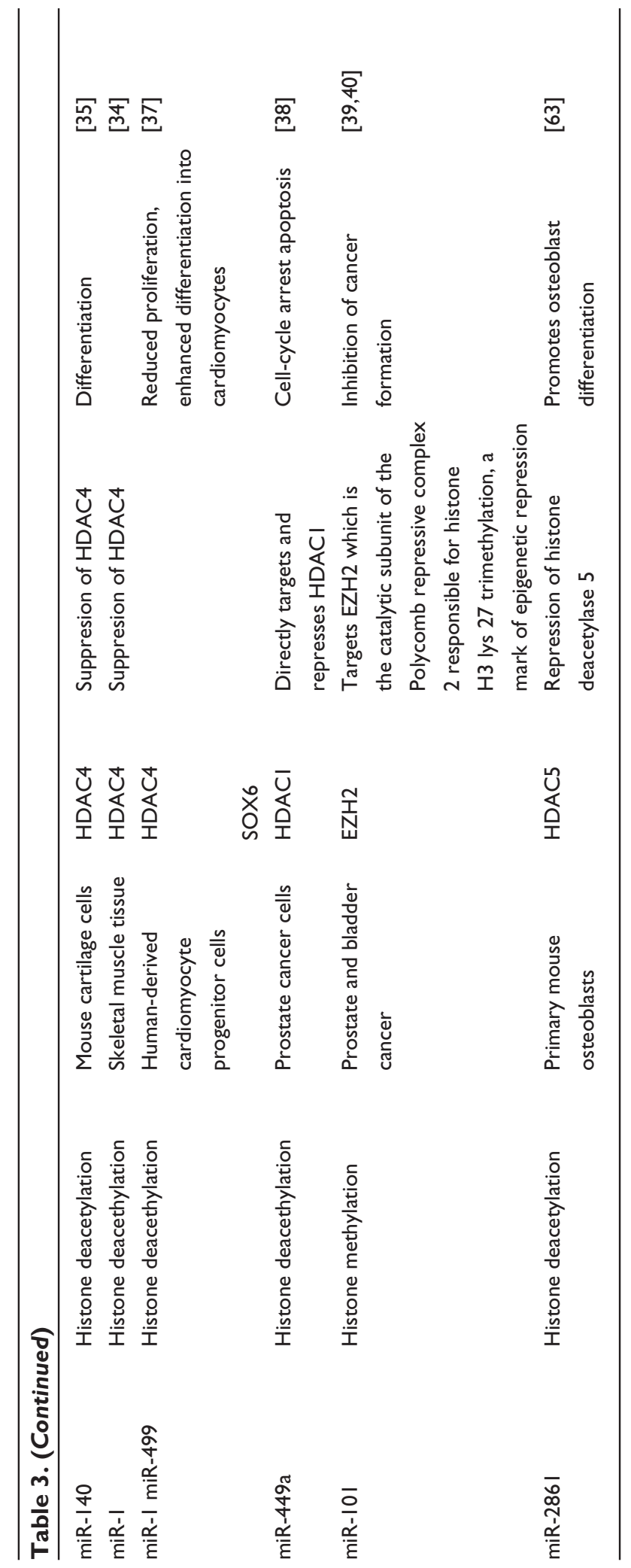

(c) The Authors Journal compilation (c) 2010 Biochemical Society 
regulatory effect of the miR-290 cluster on methylation cannot be shown in DICER-knockdown human embryonic kidney cells. This indicates that the miR-290 clusters' effect on DNMTs could be cell-type- or species-specific [32]. Recently, a completely new mechanism was suggested for regulation of gene expression by miRNAs in moss. Khraiwesh et al. propose that initiation of epigenetic silencing by DNA methylation is regulated according to the ratio of the miRNA and its target mRNA [33].

miRNAs also regulate the expression of HDACs and HMTs. HDAC4 is shown to be a direct target of miR-1 and miR-140 [34,35]. A new miRNA HDAC4 regulatory mechanism has been revealed in ALS (amyotrophic lateral sclerosis) which is the most common adult motor neuron disease. miR-206 is shown to delay the progression of ALS, and HDAC4 is both computationally and experimentally shown to be a target of miR-206. Interestingly, in miR-206 ${ }^{-/-}$animals the HDAC4 protein expression is increased in skeletal muscles, whereas Hdac4 mRNA levels were not changed. This indicated that miR-206 acts upon $\mathrm{Hdac} 4$ by translational inhibition rather than at the transcription level [36]. miR-1 and miR-499 are indicated in differentiation of cardiomyocytes, possibly by repression of HDAC4 and SOX6 genes [37].

miR-449a targets HDAC1, which is up-regulated in many cancer forms. miR-449a is down-regulated in cancer, but introduction to prostate cancer cells resulted in cell-cycle arrest and apoptosis [38]. Similarly re-expression of miR-101 in cancer models also resulted in inhibition of cancer formation. miR-101 targets EZH2, the catalytic subunit of the Polycomb repressive complex 2 responsible for histone $\mathrm{H} 3 \mathrm{Lys}^{27}$ trimethylation, a mark of epigenetic repression, and can alter the chromatin structure globally [39,40]. Li et al. [41] identified a new miRNA (miR-2861) in primary mouse osteoblasts that promotes osteoblast differentiation by repressing HDAC5 expression at the post-transcriptional level.

\section{Conclusions}

Recently, the molecular mechanisms of epigenetic regulation of miRNA expression and miRNA-mediated control of the epigenetic machinery have attracted much attention, especially in cancer research. By now it is apparent that some miRNA genes are regulated by DNA CpG island hypermethylation and chromatin modifications. Interestingly, these epigenetic marks are potential biomarkers since significant correlations with survival of cancer patients have been found. Likewise, it is also clear that miRNAs regulate various components of the epigenetic machinery and thereby contribute to the regulation of the expression of other genes.

It is essential to explore in more detail this new layer of complexity in gene regulation to improve our understanding of the regulation of the human genome. Importantly, these new insights on the intertwined relationship between miRNA and epigenetics are likely to lead to novel revolutionary anti-cancer therapeutic approaches. Such approaches may be targeting 
components of the epigenetic network to cause re-expression of miRNA tumour suppressor genes or directly targeting mature miRNAs or re-expressing miRNAs in order to directly affect target genes and regulate epigenetic feedback loops.

\section{Summary}

- $\quad$ miRNAs are small non-protein coding molecules that regulate more than $30 \%$ of the protein coding genes.

- miRNAs play an important role in many biological processes such as differentiation, organ development and proliferation.

- In cancer and some other diseases such as diabetes, neurological and cardiac diseases, a perturbed miRNA expression is found in the relevant tissues.

- Some miRNAs are regulated by epigenetic mechanisms, especially by methylation.

- Methylation status of some miRNA genes correlates with survival of cancer patients.

- miRNAs may regulate the epigenetic machinery directly or indirectly by targeting enzymes such as DNMTs or HDACs.

The Wilhelm Johannsen Centre for Functional Genome Research is established by the Danish National Research Foundation.

\section{References}

I. Griffiths-Jones, S,, Grocock, R.J., van Dongen, S., Bateman, A. and Enright, A.J. (2006) miRBase: microRNA sequences, targets and gene nomenclature. Nucleic Acids Res. 34, DI40-DI44

2. Lee, R.C., Feinbaum, R.L. and Ambros, V. (1993) The C. elegans heterochronic gene lin-4 encodes small RNAs with antisense complementarity to lin-14. Cell 75, 843-854

3. Bartel, D.P. (2004) MicroRNAs: genomics, biogenesis, mechanism, and function. Cell I I 6, 28I-297

4. Davis, B.N. and Hata, A. (2009) Regulation of microRNA biogenesis: a miRiad of mechanisms. Cell Commun. Signal. 7, 18

5. Taft., R.J., Pang, K.C., Mercer, T.R., Dinger, M. and Mattick, J.S. (20I0) Non-coding RNAs: regulators of disease. J. Pathol. 220, 126-139

6. Olena, A.F. and Patton, J.G. (2010) Genomic organization of microRNAs. J. Cell Physiol. 222, 540-545

7. Friedman, J.M. and Jones, P.A. (2009) MicroRNAs: critical mediators of differentiation, development and disease. Swiss Med Wkly I39, 466-472

8. Ruepp, A., Kowarsch, A., Schmidl, D., Bruggenthin, F., Brauner, B., Dunger, I., Fobo, G., Frishman, G., Montrone, C. and Theis, F.J. (2010) PhenomiR: a knowledgebase for microRNA expression in diseases and biological processes. Genome Biol. I I, R6

9. Kai, Z.S. and Pasquinelli, A.E. (20I0) MicroRNA assassins: factors that regulate the disappearance of miRNAs. Nat. Struct. Mol. Biol. I7, 5-10

I0. Mi, S., Li, Z., Chen, P., He, C., Cao, D., Elkahloun, A., Lu., J., Pelloso, L.A., Wunderlich, M., Huang, H. et al. (20I0) Aberrant overexpression and function of the miR-17-92 cluster in MLL-rearranged acute leukemia. Proc. Natl. Acad. Sci. U.S.A. I07, 37I0-37I5 
II. Valeri, N., Vannini, I., Fanini, F., Calore, F., Adair, B. and Fabbri, M. (2009) Epigenetics, miRNAs, and human cancer: a new chapter in human gene regulation. Mamm. Genome 20, 573-580

12. Weber, B., Stresemann, C., Brueckner, B. and Lyko, F. (2007) Methylation of human microRNA genes in normal and neoplastic cells. Cell Cycle 6, I00I-1005

13. Saito, Y., Liang, G., Egger, G., Friedman, J.M., Chuang, J.C., Coetzee, G.A. and Jones, P.A. (2006) Specific activation of microRNA-I 27 with downregulation of the proto-oncogene BCL6 by chromatin-modifying drugs in human cancer cells. Cancer Cell 9, 435-443

14. Scott, G.K., Mattie, M.D., Berger, C.E., Benz, S.C. and Benz, C.C. (2006) Rapid alteration of microRNA levels by histone deacetylase inhibition. Cancer Res. 66, I277-I28I

I5. Grady, W.M., Parkin, R.K., Mitchell, P.S., Lee, J.H., Kim, Y.H., Tsuchiya, K.D., Washington, M.K., Paraskeva, C., Willson, J.K., Kaz, A.M. et al. (2008) Epigenetic silencing of the intronic microRNA hsa-miR-342 and its host gene EVL in colorectal cancer. Oncogene 27, 3880-3888

16. Lujambio, A., Ropero, S., Ballestar, E., Fraga, M.F., Cerrato, C., Setién, F., Casado, S., Suarez-Gauthier, A., Sanchez-Cespedes, M., Git, A. et al. (2007) Genetic unmasking of an epigenetically silenced microRNA in human cancer cells. Cancer Res. 67, I424-1429

17. Toyota, M., Suzuki, H., Sasaki, Y., Maruyama, R., Imai, K., Shinomura, Y. and Tokino, T. (2008) Epigenetic silencing of microRNA-34b/c and B-cell translocation gene 4 is associated with CpG island methylation in colorectal cancer. Cancer Res. 68, 4I23-4I32

18. Lehmann, U., Hasemeier, B., Christgen, M., Müller, M., Römermann, D., Länger, F. and Kreipe, H. (2008) Epigenetic inactivation of microRNA gene hsa-mir-9-I in human breast cancer. J. Pathol. 214, 17-24

19. Bandres, E., Agirre, X., Bitarte, N., Ramirez, N., Zarate, R., Roman-Gomez, J., Prosper, F. and Garcia-Foncillas, J. (2009) Epigenetic regulation of microRNA expression in colorectal cancer. Int. J. Cancer I 25, 2737-2743

20. Lujambio, A., Calin, G.A., Villanueva, A., Ropero, S., Sánchez-Céspedes, M., Blanco, D., Montuenga, L.M., Rossi, S., Nicoloso, M.S., Faller, W.J. et al. (2008) microRNA DNA methylation signature for human cancer metastasis. Proc. Natl. Acad. Sci. U.S.A. I 05, I3556-I356 I

2I. Zhang, L., Volinia, S., Bonome, T., Calin, G.A., Greshock, J., Yang, N., Liu, C.G., Giannakakis, A., Alexiou, P., Hasegawa, K. et al. (2008) Genomic and epigenetic alterations deregulate microRNA expression in human epithelial ovarian cancer. Proc. Natl. Acad. Sci. U.S.A. 105, 7004-7009

22. Lu, L., Katsaros, D., de la Longrais, I.A., Sochirca, O. and Yu, H. (2007) Hypermethylation of let-7a-3 in epithelial ovarian cancer is associated with low insulin-like growth factor-Il expression and favorable prognosis. Cancer Res. 67, $10117-10122$

23. Roman-Gomez, J., Agirre, X., Jiménez-Velasco, A., Arqueros, V., Vilas-Zornoza, A., Rodriguez-Otero, P., Martin-Subero, I., Garate, L., Cordeu, L., San José-Eneriz, E. et al. (2009) Epigenetic regulation of microRNAs in acute lymphoblastic leukemia. J. Clin. Oncol. 27, I316-1322

24. Agirre, X., Vilas-Zornoza, A., Jiménez-Velasco, A., Martin-Subero, J.I., Cordeu, L., Gárate, L., San José-Eneriz, E., Abizanda, G., Rodríguez-Otero, P., Fortes, P. et al. (2009) Epigenetic silencing of the tumor suppressor microRNA Hsa-miR-124a regulates CDK6 expression and confers a poor prognosis in acute lymphoblastic leukemia. Cancer Res. 69, 4443-4453

25. Davalos, V. and Esteller, M.(20I0) MicroRNAs and cancer epigenetics: a macrorevolution. Curr. Opin. Oncol. 22, 35-45

26. Guil, S. and Esteller, M. (2009) DNA methylomes, histone codes and miRNAs: tying it all together. Int. J. Biochem. Cell Biol. 4I, 87-95

27. Fabbri, M., Garzon, R., Cimmino, A., Liu, Z., Zanesi, N., Callegari, E., Liu, S., Alder, H., Costinean, S., Fernandez-Cymering, C. et al. (2007) MicroRNA-29 family reverts aberrant methylation in lung cancer by targeting DNA methyltransferases 3A and 3B. Proc. Natl. Acad. Sci. U.S.A. 104, I5805-I58I0

28. Garzon, R., Liu, S., Fabbri, M., Liu, Z., Heaphy, C.E., Callegari, E., Schwind, S., Pang, J., Yu, J., Muthusamy, N. et al. (2009) MicroRNA-29b induces global DNA hypomethylation and tumor suppressor gene reexpression in acute myeloid leukemia by targeting directly DNMT3A and 3B and indirectly DNMTI. Blood I I3, 64II-64I8

29. Ng, E.K., Tsang, W.P., Ng, S.S., Jin, H.C., Yu, J., Li, J., J., Röcken, C., Ebert, M.P., Kwok, T.T. and Sung, J.J. (2009) MicroRNA-I43 targets DNA methyltransferases 3A in colorectal cancer. Br. J. Cancer I0I, 699-706 
30. Duursma, A.M., Kedde, M., Schrier, M., le Sage, C. and Agami, R. (2008) miR-I48 targets human DNMT3b protein coding region. RNA 14, 872-877

3I. Benetti, R., Gonzalo, S., Jaco, I., Muñoz, P., Gonzalez, S., Schoeftner, S., Murchison, E., Andl, T., Chen, T., Klatt, P. et al. (2008) A mammalian microRNA cluster controls DNA methylation and telomere recombination via Rbl2-dependent regulation of DNA methyltransferases. Nat. Struct. Mol. Biol. 15, 268-279

32. Sinkkonen, L., Hugenschmidt, T., Berninger, P., Gaidatzis, D., Mohn, F., Artus-Revel, C.G., Zavolan, M., Svoboda, P. and Filipowicz, W. (2008) MicroRNAs control de novo DNA methylation through regulation of transcriptional repressors in mouse embryonic stem cells. Nat. Struct. Mol. Biol. 15, 259-267

33. Khraiwesh, B., Arif, M.A., Seumel, G.I., Ossowski, S., Weigel, D., Reski, R. and Frank, W. (2010) Transcriptional control of gene expression by microRNAs. Cell I40, III-122

34. Chen, J.F., Mandel, E.M., Thomson, J.M., Wu, Q., Callis, T.E., Hammond, S.M., Conlon, F.L. and Wang, D.Z. (2006) The role of microRNA-I and microRNA-I33 in skeletal muscle proliferation and differentiation. Nat. Genet. 38, 228-233

35. Tuddenham, L., Wheeler, G., Ntounia-Fousara, S., Waters, J., Hajihosseini, M.K., Clark, I. and Dalmay, T. (2006) The cartilage specific microRNA-I 40 targets histone deacetylase 4 in mouse cells. FEBS Lett. 580, 42।4-4217

36. Williams, A.H., Valdez, G., Moresi, V., Qi, X., McAnally, J., Elliott, J.L., Bassel-Duby, R., Sanes, J.R. and Olson, E.N. (2009) MicroRNA-206 delays ALS progression and promotes regeneration of neuromuscular synapses in mice. Science 326, 1549-1554

37. Sluijter, J.P., van Mil, A., van Vliet, P., Metz, C.H., Liu, J., Doevendans, P.A. and Goumans, M.J. (2010) MicroRNA-I and -499 regulate differentiation and proliferation in human-derived cardiomyocyte progenitor cells. Arterioscler. Thromb. Vasc. Biol. 30, 859-868

38. Noonan, E.J., Place, R.F., Pookot, D., Basak, S., Whitson, J.M., Hirata, H., Giardina, C. and Dahiya, R. (2009) miR-449a targets HDAC-I and induces growth arrest in prostate cancer. Oncogene 28, $17 \mid 4-1724$

39. Varambally, S., Cao, Q., Mani, R.S., Shankar, S., Wang, X., Ateeq, B., Laxman, B., Cao, X., Jing, X., Ramnarayanan, K. et al. (2008) Genomic loss of microRNA-I0I leads to overexpression of histone methyltransferase EZH2 in cancer. Science 322, 1695-1699

40. Friedman, J.M., Liang, G., Liu, C.C., Wolff, E.M., Tsai, Y.C., Ye, W., Zhou, X. and Jones, P.A. (2009) The putative tumor suppressor microRNA-10I modulates the cancer epigenome by repressing the polycomb group protein EZH2. Cancer Res. 69, 2623-2629

4I. Li, H., Xie, H., Liu, W., Hu, R., Huang, B., Tan, Y.F., Xu, K., Sheng, Z.F., Zhou, H.D., Wu, X.P. and Luo, X.H. (2009) A novel microRNA targeting HDAC5 regulates osteoblast differentiation in mice and contributes to primary osteoporosis in humans. J. Clin. Invest. II 9, 3666-3677

42. Ando, T., Yoshida, T., Enomoto, S., Asada, K., Tatematsu, M., Ichinose, M., Sugiyama, T. and Ushijima, T. (2009) DNA methylation of microRNA genes in gastric mucosae of gastric cancer patients: its possible involvement in the formation of epigenetic field defect. Int. J. Cancer 124, 2367-2374

43. Brueckner, B., Stresemann, C., Kuner, R.., Mund, C., Musch, T., Meister, M., Sültmann, H. and Lyko, F. (2007) The human let-7a-3 locus contains an epigenetically regulated microRNA gene with oncogenic function. Cancer Res. 67, 1419-1423

44. Bueno, M.J., Pérez de CastrÅ, l., Gómez de Cedrón, M., Santos, J., Calin, G.A., Cigudosa, J.C., Croce, C.M., Fernández-Piqueras, J. and Malumbres, M. (2008) Genetic and epigenetic silencing of microRNA-203 enhances ABLI and BCR-ABLI oncogene expression. Cancer Cell I3, 496-506

45. Datta, J., Kutay, H., Nasser, M.W., Nuovo, G.J, Wang, B., Majumder, S., Liu, C.G, Volinia, S., Croce, C.M., Schmittgen, T.D., Ghoshal, K. and Jacob, S.T. (2008) Methylation mediated silencing of MicroRNA-I gene and its role in hepatocellular carcinogenesis. Cancer Res. 68, 5049-5058

46. Fazi, F., Racanicchi, S., Zardo, G., Starnes, L.M., Mancini, M., Travaglini, L., Diverio, D., Ammatuna, E., Cimino, G., Lo-Coco, F. et al. (2007) Epigenetic silencing of the myelopoiesis regulator microRNA-223 by the AMLI/ETO oncoprotein. Cancer Cell. 12, 457-466 
47. Furuta, M., Kozaki, K.I., Tanaka, S., Arii, S., Imoto, I. and Inazawa, J. (20I0) miR-I 24 and miR-203 are epigenetically silenced tumor-suppressive microRNAs in hepatocellular carcinoma. Carcinogenesis 3I, 766-776

48. Hashimoto, Y., Akiyama, Y., Otsubo, T., Shimada, S. and Yuasa, Y. (2010) Involvement of epigenetically silenced microRNA-I8Ic in gastric carcinogenesis. Carcinogenesis 31 , 777-784

49. Hsu, P.Y., Deatherage, D.E., Rodriguez, B.A., Liyanarachchi, S., Weng, Y.I , Zuo, T., Liu, J., Cheng, A.S. and Huang, T.H. (2009) Xenoestrogen-induced epigenetic repression of microRNA-9-3 in breast epithelial cells. Cancer Res. 69, 5936-5945

50. Huang, Y.W., Liu, J.C., Deatherage, D.E., Luo, J., Mutch, D.G., Goodfellow, P.J., Miller, D.S. and Huang, T.H. (2009) Epigenetic repression of microRNA-I29-2 leads to overexpression of SOX4 oncogene in endometrial cancer. Cancer Res. 69, 9038-9046

5I. Iorio, M.V., Visone, R., Di Leva, G., Donati, V., Petrocca, F., Casalini, P., Taccioli, C., Volinia, S., Liu, C.G., Alder, H. et al. (2007) MicroRNA signatures in human ovarian cancer. Cancer Res. 67, 8699-8707

52. Kozaki, K., Imoto, I., Mogi, S., Omura, K. and Inazawa, J. (2008) Exploration of tumor-suppressive microRNAs silenced by DNA hypermethylation in oral cancer. Cancer Res. 68, 2094-2I05

53. Lee, K.H., Lotterman, C., Karikari, C., Omura, N., Feldmann, G., Habbe, N., Goggins, M.G., Mendell, J.T. and Maitra, A. (2009) Epigenetic silencing of MicroRNA miR-I07 regulates cyclindependent kinase 6 expression in pancreatic cancer. Pancreatology 9, 293-30I

54. Lodygin, D., Tarasov, V., Epanchintsev, A., Berking, C., Knyazeva, T., Körner, H., Knyazev, P., Diebold, J. and Hermeking, H. (2008) Inactivation of miR-34a by aberrant CpG methylation in multiple types of cancer. Cell Cycle. 7, 259I-2600

55. Lujambio, A., Calin, G.A., Villanueva, A., Ropero, S., Sánchez-Céspedes, M., Blanco, D., Montuenga, L.M., Rossi, S., Nicoloso, M.S., Faller, W.J. et al. (2008) A microRNA DNA methylation signature for human cancer metastasis. Proc. Natl. Acad. Sci. U.S.A. I05, I3556-1356 I

56. Meng, F., Wehbe-Janek, H., Henson, R., Smith, H. and Patel, T. (2008) Epigenetic regulation of microRNA-370 by interleukin-6 in malignant human cholangiocytes. Oncogene 27, 378-386

57. Rauhala, H.E., Jalava, S.E., Isotalo, J., Bracken, H., Lehmusvaara, S., Tammela, T.L., Oja, H. and Visakorpi, T. (2010) miR-I93b is an epigenetically regulated putative tumor suppressor in prostate cancer. Int. J. Cancer, in press

58. Saito, Y., Friedman, J.M., Chihara, Y., Egger, G., Chuang, J.C. and Liang, G. (2009) Epigenetic therapy upregulates the tumor suppressor microRNA-126 and its host gene EGFL7 in human cancer cells. Biochem. Biophys. Res. Commun. 379, 726-73I

59. Saito, Y., Suzuki, H., Tsugawa, H., Nakagawa, I., Matsuzaki, J., Kanai, Y. and Hibi, T. (2009) Chromatin remodeling at Alu repeats by epigenetic treatment activates silenced microRNA-5 I 2$5 p$ with downregulation of $\mathrm{Mcl}-\mathrm{I}$ in human gastric cancer cells. Oncogene 28, 2738-2744

60. Tsai, K.W., Kao, H.W., Chen, H.C., Chen, S.J. and Lin, W.C. (2009) Epigenetic control of the expression of a primate-specific microRNA cluster in human cancer cells. Epigenetics 4, 587-592

6I. Vrba, L., Jensen, T.J., Garbe, J.C., Heimark, R.L., Cress, A.E., Dickinson, S., Stampfer, M.R. and Futscher, B.W. (20I0) Role for DNA methylation in the regulation of miR-200c and miR-I4I expression in normal and cancer cells. PLoS One 5, e8697

62. Williams, A.H., Valdez, G., Moresi, V., Qi, X., McAnally, J., Elliott, J.L., Bassel-Duby, R., Sanes, J.R. and Olson, E.N. (2009) MicroRNA-206 delays ALS progression and promotes regeneration of neuromuscular synapses in mice. Science 326, I549-I 554

63. Li, H., Xie, H., Liu, W., Hu, R., Huang, B., Tan, Y.F., Xu, K., Sheng, Z.F., Zhou, H.D., Wu, X. P., Luo, X.H. (2009) A novel microRNA targeting HDAC5 regulates osteoblast differentiation in mice and contributes to primary osteoporosis in humans. J. Clin. Invest. I I 9, 3666-3677 
